\title{
To study the influence of access use of internet on academic performance of adolescents
}

See end of the paper for authors' affiliations VARSHA GOEL

Department of Home Science, Shri Ram College, MUZAFFARNAGAR (U.P.) INDIA

Email : varshag79@gmail.com
ABSTRACT : Present study was conducted to know the influence of access use of internet on academic performance among intermediate adolescents. The study also focused to examine the gender differences among adolescents on excess usage of internet. Undoubtedly, Internet has brought a great revolution worldwide and the world is in its feast. It has delimited the whole world and made a man able to access anywhere, anytime and in any field of life. Facilities are available at one's door step. But, it is well said that excess of everything is bad. Likewise, excess use of internet has become a problem today. This part of research contribution will analyze the reality and gap between the positive and negative impact and aspects of usage of internet on education. The sample comprised of 300 adolescents. Their responses to the "Internet Usage Scale" and GPA for the previous year were collected and analyzed using methods including descriptive statistics. The results suggested that excess use of internet was a significantly negatively correlated with academic performance of intermediate adolescents. Results also suggested gender difference in excess usage of internet. Male adolescents had higher user of internet than female ones. The paper concludes with recommendations for future study in order to better understand the growing impact of internet on our youth

KEY WORDS: Excess use of internet, Academic performance, Adolescents

- HOW TO CITE THIS PAPER : Goel, Varsha and Garg, Ritu (2015). To study the influence of access use of internet on academic performance of adolescents. Asian J. Home Sci., 10 (2) : 449-455. 